\title{
Making ES cells 'ethically sound'
}

Two research groups present alternative approaches for the preparation of embryonic stem (ES) cells that they hope may help bypass the social and political morass surrounding this technology.

The Bush administration's decision in 2001 to limit federally funded research to the use of only a small number of existing ES cell lines has posed a major obstacle to American biologists. This policy is a manifestation of the opposition to the process by which these are isolated from human blastocysts because the procedure causes the destruction of an embryo, which some argue amounts to ending a human life. This has left ES cell researchers scrambling, with some scientists pushing for active policy reform, while others explore workaround strategies that might prove more ethically palatable to the opposition.

William Hurlbut, a member of the President's Council on Bioethics, suggested one such approach-altered nuclear transfer (ANT), a modified version of nuclear transfer using somatic donor cells in which a key developmental gene has been knocked out, making normal embryonic implantation and development impossible. "It was sort of a thought experiment, proposed as a possibility, but nobody's really tried it before," explains MIT researcher Rudolf Jaenisch. "The idea was that you make a biological construct which doesn't resemble an embryo but can still make embryonic stem cells." In a new paper in Nature, Jaenisch and coauthor Alexander Meissner demonstrate the first successful derivation of mouse ES cells via ANT (Meissner \& Jaenisch, 2005). They infected mouse fibroblasts with a lentiviral construct that conditionally expresses a short inhibitory (si)RNA construct targeting $C d x 2$ - a gene specific to the cell lineage responsible for mediating uterine implantation of developing embryos. They used these fibroblasts for nuclear transfer into wild-type oocytes, yielding morphologically abnormal blastocysts incapable of implantation; however, these blastocysts could be dissociated to produce pluripotent ES cell

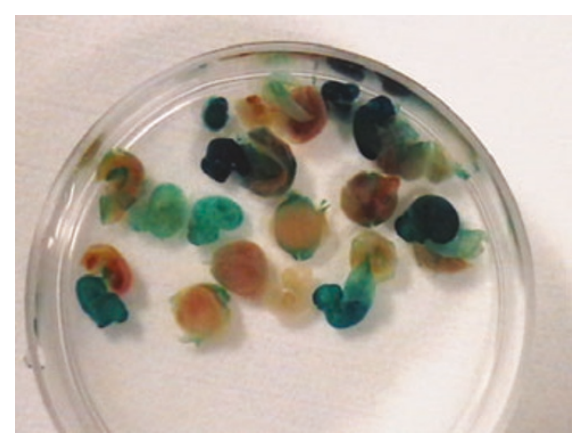

Figure 1 | Chimeric 11.5-day-old mouse embryos generated from blastomere-derived ES cell lines by Lanza's group. $\beta$-galactosidase staining was used to indicate ES-derived tissues. Reprinted with permission from Nature.

lines. The researchers used these to generate chimeric mice in which the ES cells were found to contribute to most cell lineages. Of course, the lack of $C d x 2$ expression meant that viable mice could not be generated from this cell line alone, but by eliminating siRNA expression, Jaenisch's group was able to obtain mice entirely derived from these ANT ES cells.

A second article in the same issue of Nature offers a different approach for obtaining ES cells. Preimplantation genetic diagnosisthe removal of a blastomere, or single cell from an eight-cell blastocyst, for diagnostic purposes - is a standard procedure at in vitro fertilization clinics, and has been repeatedly shown not to endanger development of the biopsied embryo. Robert Lanza and his colleagues at Advanced Cell Technology and the University of Wisconsin used such biopsies as a starting point, cultivating both embryonic and nonembryonic stem cells from mouse blastomeres (Chung et al., 2005). Although the success rate was relatively low, the ES cell lines that they obtained maintained complete pluripotency and could be implanted to generate chimeras (Fig. 1) with widespread ES cell contribution to different tissues. "This is the first time anyone has found a nondestructive way to create stem cells," says Lanza, "and they were absolutely identical to normal embryonic stem cells by all criteria and all tests."

Together, these two studies offer some hope for ES cell research, but both also face opposition-even some from the research community. In a 2004 letter to the New England Journal of Medicine (Melton et al., 2004), several scientists from the Harvard Stem Cell Institute criticized Hurlbut's ANT proposal for failing to resolve core controversies of the ES cell debate-specifically, the belief of some people that any manner of interference with an embryo's capacity to develop is fundamentally unethical. The authors added, "We see no basis for concluding that the action of $C d x 2$ (or indeed any other gene) represents a transition point at which a human embryo acquires moral status." Jaenisch concedes that the issue remains sticky: "It clearly works...but it comes down to the implementation, how people view this politically." But he adds, "it might help resolve the problem, and I think that would be worthwhile to pursue."

Lanza has also had to defend his approach against critics who express concern about the biopsied embryos, but he responds: "You would in no way influence or add any layer of risk to that embryo... [and] you would have stem cells that would not only benefit stem cell researchers worldwide, but you would [also] have lines that are genetically identical to the child." Like Jaenisch, Lanza can only conclude, "I think we should let the facts speak for themselves... there has been some misinformation, but if they have the facts-let the powers that be make these decisions."

\section{Michael Eisenstein}

\section{RESEARCH PAPERS}

Chung, Y. et al. Embryonic and extraembryonic stem cell lines derived from single mouse blastomeres. Nature; published online 16 October 2005.

Meissner, A. \& J aenisch, R. Generation of nuclear transfer-derived pluripotent ES cells from cloned $\mathrm{Cd} \times 2$ deficient blastocysts. Nature; published online 16 October 2005.

Melton, D.A. et al. Altered nuclear transfer in stemcell research-a flawed proposal. N. Engl. J. Med. 351, 2791-2792 (2004). 